\title{
PROGRAMA SOCIAL FEDERAL DE TRANSFERÊNCIA DE RENDA BOLSA FAMÍLIA E O CONSUMO NO BRASIL: A PRESENÇA DA TEORIA DE JUSTIÇA DE JOHN RAWLS
}

Social Program Federal transfer income family scholarship and consumption in Brazil: the presence of John Rawls Theory of Justice

Cleide Calgaro *

Thadeu Weber $* *$

Resumo: Neste estudo evidencia-se a inserção da teoria de Justiça como equidade de John Rawls através dos princípios da liberdade igual, da igualdade equitativa de oportunidade e da diferença no Programa Social Federal de Transferência de Renda Bolsa Família e o aumento do consumo dos beneficiários desse programa social.

Palavras-chave: John Rawls. Bolsa Família. Consumo. Direitos Fundamentais.

\begin{abstract}
Neste estudo evidencia-se a inserção da teoria de Justiça como equidade de John Rawls através dos princípios da liberdade igual, da igualdade equitativa de oportunidade e da diferença no Programa Social Federal de Transferência de Renda Bolsa Família e o aumento do consumo dos beneficiários desse programa social.

Palavras-chave: John Rawls. Bolsa Família. Consumo. Direitos

Fundamentais.
\end{abstract}

* Pós-doutoranda em Filosofia na PUC/RS. E-mail: ccalgaro@ucs.br

** Doutor em Filosofia pela Universidade Federal do Rio Grande do Sul (UFRGS). Professor na PósGraduação em Filosofia e Direito da PUC/RS. E-mail: weberth @ pucrs.br

\begin{tabular}{|c|c|l|l|l|l|}
\hline intuitio & $\begin{array}{c}\text { ISSN } \\
1983-4012\end{array}$ & Porto Alegre & Vol.8 $-\mathrm{N}^{\circ} .1$ & $\begin{array}{c}\text { Junho } \\
2015\end{array}$ & p.198-217 \\
\hline
\end{tabular}




\section{Introdução}

No presente trabalho pretende-se fazer uma análise do Programa Social Federal de Transferência de Renda Bolsa Família. Se há presença dos princípios da liberdade, da igualdade equitativa de oportunidades e da diferença advindos da teoria de Justiça como Equidade de John Rawls. Por fim, se quer abordar a consistência do Programa Bolsa Família com a perspectiva do justo.

Inicialmente se analisa a presença da teoria de justiça de Rawls e os seus principais aspectos juntamente com os principais pontos do Programa Bolsa Família. Após, se faz um exame, a partir de diversos indicadores sociais, como IPEA, IBASE, MDS, entre outros, para se verificar se houve um aumento do consumo no Brasil, a partir da implementação desse Programa Social.

O método de abordagem utilizado será o analítico-dedutivo e o autor de base a ser estudado é John Rawls, do ponto de vista da Justiça Distributiva com alicerce no princípio da diferença, da igualdade de oportunidades e da liberdade igual, verificando como os Estados promovem essas políticas redistributivas. O intuito é avaliar até que ponto a teoria de justiça do autor pode servir de marco teórico para fundamentar as referidas políticas públicas sociais no Brasil. O presente trabalho é fruto da pesquisa de Pósdoutoramento em Filosofia Social e Política, realizado na Pontifícia Universidade Católica do Rio Grande do Sul sob a supervisão do Professor Dr. Thadeu Weber.

\section{O Programa Bolsa Família no Brasil e a Teoria de Justiça de John Rawls}

Na presente seção será objeto de apreciação os princípios da justiça como equidade, com base nos princípios da liberdade igual, da igualdade equitativa de oportunidade e o princípio da diferença, também, se analisa o Programa Social Federal de Transferência de renda Bolsa Família e a sua articulação com a teoria da justiça de Rawls.

\subsection{Os princípios de justiça como equidade de John Rawls}

$\mathrm{Na}$ teoria de justiça de Rawls, a justiça é a primeira virtude as instituições sociais. Do igual modo, não se permite que os sacrifícios atribuídos a alguns tenham menor valor que o total das vantagens que são fruídas por muitos. Logo, para que uma sociedade seja justa, as liberdades de cidadania igual devem ser consideradas invioláveis onde os direitos sejam assegurados pela justiça, uma vez que "não estão sujeitos

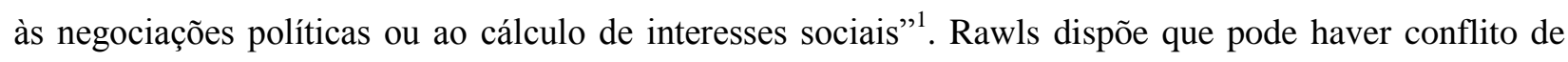
interesses, pois os indivíduos não se tornam indiferentes no que se refere à forma de como os benefícios

${ }^{1}$ RAWLS, John. Uma teoria da Justiça. São Paulo: Martins Fonte, 2002, p. 04.

\begin{tabular}{|c|c|c|c|c|c|}
\hline intuitio & $\begin{array}{c}\text { ISSN } \\
1983-4012\end{array}$ & Porto Alegre & Vol.8 $-\mathrm{N}^{\mathrm{o}} .1$ & $\begin{array}{c}\text { Junho } \\
2015\end{array}$ & p.198-217 \\
\hline
\end{tabular}


produzidos através da colaboração mútua devem ser distribuídos. Logo, uma sociedade é bem ordenada quando é regulada por uma "concepção pública de justiça" 2 .

É importante frisar que o consenso nas concepções de justiça não é o único requisito para uma sociedade bem ordenada. É preciso que os planos dos indivíduos se encaixem uns nos outros e que a execução desses planos seja a de buscar os fins sociais de forma eficiente e coerente com a justiça. Existe, também, a necessidade de uma cooperação social, a qual deve ser estável.

Esse consenso permite a justiça acontecer pela posição original, que constitui o status quo inicial adequado devendo assegurar um consenso básico equitativo. Pode-se afirmar que a posição original é uma situação hipotética na qual é possível um acordo entre os indivíduos acerca dos princípios da justiça. Contudo, para que isso ocorra são imprescindíveis estratégias para neutralizar os elementos que impossibilitam a chegada a esse acordo, isto é, as diferentes posições sociais e as convicções substantivas. Assim sendo, se subtraírem as posições e as convicções e se adotar o ponto de imparcialidade sob o "véu da ignorância"3 dos indivíduos na sociedade, seria possível se chegar a um consenso e atingir os princípios da justiça. Ou seja, se nenhum indivíduo conhecer a sua posição na sociedade (sua situação de classe ou estatuto social), e não soubesse a parte que lhe cabe na distribuição de atributos e talentos naturais (como por exemplo, a inteligência, a força, etc.) isso permitiria que os princípios da justiça fossem escolhidos sob o véu da ignorância. Portanto, haverá a garantia de que nenhuma pessoa seja beneficiada ou mesmo prejudicada na escolha daqueles princípios pelos resultados do acaso natural ou pela contingência das circunstâncias sociais.

Assim sendo, a única forma dos indivíduos, em uma posição original, escolherem os princípios da justiça, seria escolhê-los sob o véu da ignorância, segundo o qual esses indivíduos ignorariam suas circunstâncias pessoais anteriores a essa situação hipotética. Logo, esses indivíduos desconheceriam suas condições financeiras e seus dotes naturais. Importante se frisar que, Rawls não visa o bem supostamente existente, mas procura construir um conceito de justo a partir do uso da razão e da vontade dos indivíduos. De igual modo, não se discute se a "posição original" seria uma posição imaginária ou não, mas sim se no mundo se poderiam construir princípios que são fundamentados na igualdade, na liberdade e no interesse de cada pessoa. Além do que, é importante se saber se essas premissas aceitas levam ou não aos princípios da justiça.

Rawls assevera que o primeiro objeto dos princípios da justiça social é a "estrutura básica da sociedade" ${ }^{4}$, onde a ordenação das instituições sociais parte de um esquema de cooperação. Esses

\footnotetext{
${ }^{2}$ RAWLS, John. Uma teoria da Justiça. São Paulo: Martins Fonte, 2002.

${ }^{3}$ De algum modo, devemos anular os efeitos das contingências específicas que colocam os homens em posição de disputa, tentando-os a explorar as circunstâncias naturais e sociais em seu próprio benefício. (RAWLS, John. Uma teoria da Justiça. São Paulo: Martins Fonte, 2002, p. 147).

${ }^{4}$ RAWLS, John. Uma teoria da Justiça. São Paulo: Martins Fonte, 2002.
}

\begin{tabular}{|c|c|c|c|c|c|}
\hline intuitio & $\begin{array}{c}\text { ISSN } \\
1983-4012\end{array}$ & Porto Alegre & Vol.8 $-\mathrm{N}^{\circ} .1$ & $\begin{array}{c}\text { Junho } \\
2015\end{array}$ & p.198-217 \\
\hline
\end{tabular}


princípios devem orientar a atribuição tanto de direitos como de deveres nessas instituições, além de determinar a distribuição de forma adequada de benefícios e encargos da vida social. Rawls traz a formulação dos princípios de justiça da seguinte forma:

a. Todas as pessoas têm igual direito a um projeto inteiramente satisfatório de direitos e liberdades básicas iguais para todos, projeto este compatível como todos os demais; e, nesse projeto, as liberdades políticas, e somente estas, deverão ter seu valor equitativo garantido.

b. As desigualdades sociais e econômicas devem satisfazer dois requisitos: primeiro, devem estar vinculadas a posições e cargos aberto a todos, em condições de igualdade equitativa de oportunidades; e, segundo devem representar o maior benefício possível aos membros menos privilegiados da sociedade 5 .

O primeiro princípio é o da liberdade igual e o segundo princípio se subdivide em duas partes: a primeira trata do princípio da igualdade equitativa de oportunidades e a segunda parte, do princípio da diferença. Portanto, os princípios vão ser utilizados se observando a estrutura serial ou lexográfica, onde o primeiro antecede ao segundo, como se pode observar abaixo:

Esse princípio deve obedece a uma ordenação serial, o primeiro antecede ao segundo. Essa ordenação significa que as violações das liberdades básicas igual protegidas pelo primeiro princípio não podem ser justificadas nem compensadas por maiores vantagens econômicas e sociais. Essas liberdades têm um âmbito central de aplicação dentro do qual ela só podem ser limitadas ou comprometidas quando entram em conflito com outras liberdades básicas. Uma vez que podem ser limitadas quando se chocam umas com as outras, nenhuma dessas liberdades é absoluta; entretanto, elas são ajustadas de modo a formar um único sistema, que deve ser o mesmo para todos ${ }^{6}$.

Essa ordem lexográfica implica na prioridade da justiça sobre o bem. Portanto, a ordem lexográfica vem garantir que o primeiro princípio seja completamente satisfeito antes que se passe para o segundo, ou seja, se assegure que a inviolabilidade das liberdades individuais está acima de todos os ajustes sociais que busquem a equidade. $\operatorname{Rawls}^{7}$ corrobora afirmando que esses dois princípios vão se aplicar a estrutura básica da sociedade e vão governar a distribuição de direitos e mesmo de deveres que irão regular todas as vantagens econômicas e mesmo as vantagens sociais.

O princípio da "liberdade igual" visa garantir igual sistema de liberdade e mesmo de direitos, sendo de forma mais ampla possível, pois a liberdade igual seria para todos os indivíduos. Esse princípio traz em seu bojo, a liberdade política, a liberdade de reunião, a liberdade de expressão, a liberdade de pensamento e a liberdade consciência, ou seja, se refere às liberdades básicas dos cidadãos que visam "a

\footnotetext{
${ }^{5}$ RAWLS, John. Uma teoria da Justiça. São Paulo: Martins Fonte, 2002, p. 47-48.

${ }^{6}$ RAWLS, John. Uma teoria da Justiça. São Paulo: Martins Fonte, 2002, p. 65.

${ }^{7}$ RAWLS, John. Uma teoria da Justiça. São Paulo: Martins Fonte, 2002.
}

\begin{tabular}{|c|c|c|c|c|c|}
\hline intuitio & $\begin{array}{c}\text { ISSN } \\
1983-4012\end{array}$ & Porto Alegre & Vol.8 $-\mathrm{N}^{\mathrm{o}} .1$ & $\begin{array}{c}\text { Junho } \\
2015\end{array}$ & p.198-217 \\
\hline
\end{tabular}


proteção contra a opressão psicológica, o direito a propriedade privada e a proteção contra a prisão e a detenção arbitrárias, de acordo com o conceito de estabilidade de direito" ${ }^{\natural}$.

O princípio da "igualdade equitativa oportunidade" apresenta a função de neutralizar os efeitos da distribuição inicial de posições privilegiadas, ou seja, o mesmo se refere à vinculação de cargos e posições abertos a todos as pessoas na sociedade. Rawls entende que o princípio da igualdade equitativa de oportunidade assegura que apenas as pessoas com os mesmos níveis de talentos e habilidades disponham chances equivalentes na vida. Mas, Rawls não faz um nivelamento das realizações e deixa espaço para distinções que são feitas com alicerce nos talentos naturais. Portanto, permanece o problema das pessoas melhores dotadas de talentos e, é nesse ponto, que adentra o princípio da diferença.

Já, o "princípio da diferença" assegura que as eventuais desigualdades econômicas que existem na distribuição de renda e de riquezas somente podem ser aceitas caso possam beneficiar aqueles que estejam em maiores desvantagens. Ou seja, esse princípio estaria vinculado a uma justiça distributiva, onde os que estão em uma posição melhor somente podem aumentar os seus ganhos se isso vier a implicar uma vantagem às pessoas menos favorecidas na sociedade. Consequentemente, as desigualdades seriam justificadas por uma igualdade onde todos têm acesso aos bens primários ${ }^{9}$. Assim sendo, o princípio da diferença significa que os bens primários devem ser distribuídos de forma igualitária exceto se uma distribuição desigual desses bens vier a beneficiar os menos favorecidos na sociedade. Portanto, é assegurado que as eventuais desigualdades econômicas e sociais existentes na distribuição de renda e de riquezas somente podem ser aceitas caso possam beneficiar aqueles que estejam em maiores desvantagens, ou seja, os menos favorecidos socialmente. Assim sendo, as desigualdades são inerentes às sociedades, seja em função dos diferentes talentos e capacidades, seja diante da necessidade de se minimizar a eficiência das estruturas econômicas e sociais.

Rawls assevera que "se certas desigualdades de riqueza e diferenças de autoridade colocam todos em melhores condições do que nessa posição inicial hipotética, então elas estão de acordo com a concepção geral" ${ }^{\text {"10 }}$. Prossegue salientando que a concepção de justiça não visa impor restrições quanto aos tipos de desigualdades existentes, mas exige, na verdade, que a posição de todas as pessoas deva ser melhorada. Isto é, podem existir desigualdades sociais e elas podem ser valorizadas desde que os menos favorecidos sejam com isso, beneficiados na sociedade.

Portanto, os dois princípios se aplicam às instituições, mas tem certas consequências. Esses direitos e deveres estabelecidos pelas instituições da sociedade é que determinam se os homens são livres

\footnotetext{
${ }^{8}$ RAWLS, John. Uma teoria da Justiça. São Paulo: Martins Fonte, 2002, p. 65.

${ }^{9}$ Rawls coloca dois tipos de bens primários: os sociais (é que ele trabalha em sua teoria) e os bens primários naturais.

${ }^{10}$ RAWLS, John. Uma teoria da Justiça. São Paulo: Martins Fonte, 2002, p.67.
}

\begin{tabular}{|c|c|c|c|c|c|}
\hline intuitio & $\begin{array}{c}\text { ISSN } \\
1983-4012\end{array}$ & Porto Alegre & Vol.8 $-\mathrm{N}^{\circ} .1$ & $\begin{array}{c}\text { Junho } \\
2015\end{array}$ & p.198-217 \\
\hline
\end{tabular}


ou não. Para Rawls, "a liberdade é um certo padrão de forma sociais"11. Destarte, o primeiro princípio exige certos tipos de regras, isto é, aquelas que definem as liberdades básicas, que se aplicam igualmente a todos e, que permitem que as liberdades mais abrangentes possam ser compatíveis com a liberdade dos demais cidadãos. O segundo princípio se aplica à distribuição de riqueza e renda e a responsabilidade.

Existem no Brasil as desigualdades sociais, mas as políticas redistributivas representam a presença do princípio da diferença em Rawls, onde pela máxima do autor: se podem ter as desigualdades desde que os "menos favorecidos" tenham benefícios na sociedade, ou seja, beneficiar ao máximo de pessoas menos favorecidos na sociedade. Rawls ${ }^{12}$ apresenta possibilidades para entender o princípio da diferença discorrendo acerca das diferenças entre a "eficiência" e a "equidade". O autor argumenta que cada pessoa, preferindo possuir mais bens acharia sensato distribuir os bens de forma igual a todos, evitando ficar com menos, mas como as desigualdades são inerentes às sociedades (devido ao fato de diferenças de capacidades ou de maximizar a eficiência das estruturas econômicas) e prevendo que elas ocorrerão, as pessoas devem exercer uma antecipação do direito de veto às situações que vão implicar em prejuízos. Deste modo, a elevação do salário mínimo, os programas sociais de renda mínima, como por exemplo, o programa Bolsa Família, com todos os seus problemas, representam um conteúdo mínimo que o Estado promove para contrapor a concentração de renda provocada pelas forças sociais de mercado.

No momento posterior se averigua o Programa Social Federal de Transferência de Renda Bolsa Família no contexto brasileiro analisando seus principais aspectos e a forma de aplicação na sociedade atual.

\subsection{O programa social federal de transferência de renda Bolsa Família}

O Programa Social Federal de Transferência de Renda Bolsa Família juntou uma série de programas sociais criados pelos Municípios bem como pelo Governo Federal durante a presidência de Fernando Henrique Cardoso. No ano de 1995, na cidade paulista de Campinas e no Distrito Federal, organizou-se a transferência de recursos para as famílias como garantia da frequência das crianças nas escolas $^{13}$. Em 1996, em Belo Horizonte, foi adotado o programa Bolsa Escola. No mesmo ano o Governo Federal lançou o Programa de Erradicação do Trabalho Infantil. No ano de 1998 surgiu o Programa Nacional de Garantia de Renda Mínima, criado sob a responsabilidade do Ministério da Educação. Já, no ano de 2001, tem-se o Programa Nacional de Renda Mínima que foi vinculado à educação (Bolsa-Escola), e, no mesmo ano, criou-se o Programa Nacional de Renda Mínima vinculado à saúde (Bolsa

\footnotetext{
${ }^{11}$ RAWLS, John. Uma teoria da Justiça. São Paulo: Martins Fonte, 2002, p.68.

${ }^{12}$ RAWLS, John. Uma teoria da Justiça. São Paulo: Martins Fonte, 2002.

${ }^{13}$ CALGARO, Cleide. Programas de transferência de renda: atores e políticas públicas na reconfiguração do estado contemporâneo. Curitiba: Juruá, 2013.
}

\begin{tabular}{|c|c|c|c|c|c|}
\hline intuitio & $\begin{array}{c}\text { ISSN } \\
1983-4012\end{array}$ & Porto Alegre & Vol. $-\mathrm{N}^{\circ} .1$ & $\begin{array}{c}\text { Junho } \\
2015\end{array}$ & p.198-217 \\
\hline
\end{tabular}


Alimentação). Em 2002, foi criado o Programa Auxílio Gás e, em 2003 se iniciou o Programa Nacional de Acesso à Alimentação. Em outubro de 2003, editado por Medida Provisória e convertido em Lei em janeiro de 2004, Lei 10.836, datada de 09 de janeiro, surge o Programa Bolsa Família que veio para unificar os diversos Programas Federais e permitir uma redução dos custos de aplicação. Após, foi regulado pelo Decreto $\mathrm{n}^{\circ} 5.209 / 04^{14}$.

O Programa Bolsa Família (PBF), segundo dados do Ministério do Desenvolvimento Social e Combate à Fome (MDS), é programa social de transferência de renda direta que vai beneficiar famílias brasileiras que vivem em situação de pobreza e de extrema pobreza. "O Bolsa Família integra o Plano Brasil Sem Miséria, que tem como foco de atuação os milhões de brasileiros com renda familiar per capita inferior a $\mathrm{R} \$ 77,00$ reais mensais e, está baseado na garantia de renda, inclusão produtiva e no acesso aos serviços públicos" ${ }^{\prime 15}$. Esse programa de transferência de renda possui três eixos basilares: a transferência de renda que visa promover o alívio imediato da pobreza, ou seja, do cidadão que está em vulnerabilidade social; as condicionalidades (contrapartida do beneficiário para receber o programa social) que reforçam o acesso a direitos sociais básicos nas áreas de educação, saúde e assistência social; e, as ações e programas complementares que objetivam o desenvolvimento social das famílias, de maneira que, os beneficiários consigam superar a situação de vulnerabilidade social e que se inserir no seio social brasileiro ${ }^{16}$.

Conforme dados do MDS, todos os meses é feito depósito, pelo Governo Federal, em favor das famílias beneficiadas (que fazem o cadastro nos municípios através do Cadastro Único (CadÚnico17) para Programas Sociais do Governo Federal18). Esse saque, feito por cartão magnético, é emitido preferencialmente à mulher, além do que, o valor é repassado dependendo do tamanho da família, da idade se seus membros e da renda. Igualmente, existem benefícios que são específicos para as famílias que possuem crianças, para gestantes, para mães que amamentam e para jovens com até 17 anos de idade ${ }^{19}$. Não se pode esquecer que, o Governo Federal infere condicionalidades aos beneficiários desse programa, sendo as mesmas um compromisso assumido pela família beneficiária e, também, pelo Poder Público. A função do Poder Público seria ampliar os direitos sociais básicos dessas famílias. Mas, de outra banda, as famílias devem concordar e cumprir esses compromissos, pois esse é o requisito para continuar recebendo o benefício. Essas condicionalidades, também, vêm responsabilizar o poder público para que haja a oferta

\footnotetext{
${ }^{14}$ CALGARO, Cleide. Programas de transferência de renda: atores e políticas públicas na reconfiguração do estado contemporâneo. Curitiba: Juruá, 2013.

${ }^{15}$ BRASIL. MDS. <http://www.mds.gov.br/bolsafamilia >. Acesso em: 21 jun. 2014.

${ }^{16}$ BRASIL. MDS. <http://www.mds.gov.br/bolsafamilia $>$. Acesso em: 21 jun. 2014.

17 O CadÚnico é um cadastro que vale para todos os programas sociais do Governo Federal. Esse meio é um instrumento que identifica as famílias em situação de vulnerabilidade social, permitindo o acesso delas a vários programas sociais.

${ }_{18}$ http://www.mds.gov.br/bolsafamilia/resolveuid/1169e4d98311fe31e82e6712f9aa7c4a

${ }^{19}$ BRASIL. MDS. <http://www.mds.gov.br/bolsafamilia〉. Acesso em: 21 jun. 2014.
}

\begin{tabular}{|c|c|c|c|c|c|}
\hline intuitio & $\begin{array}{c}\text { ISSN } \\
1983-4012\end{array}$ & Porto Alegre & Vol.8 $-\mathrm{N}^{\mathrm{o}} .1$ & $\begin{array}{c}\text { Junho } \\
2015\end{array}$ & p.198-217 \\
\hline
\end{tabular}


dos serviços públicos de saúde, educação e assistência social, que são direitos básicos do cidadão brasileiro.

Segundo o MDS na área de saúde, "as famílias beneficiárias assumem o compromisso de acompanhar o cartão de vacinação e o crescimento e desenvolvimento das crianças menores de 7 anos. As mulheres na faixa de 14 a 44 anos também devem fazer o acompanhamento e, se gestantes ou nutrizes (lactantes), devem realizar o pré-natal e o acompanhamento da sua saúde e do bebê" ${ }^{20}$. Já, na área da educação "todas as crianças e adolescentes entre 6 e 15 anos devem estar devidamente matriculados e com frequência escolar mensal mínima de $85 \%$ da carga horária. Os estudantes entre 16 e 17 anos devem ter frequência de, no mínimo, 75\%."21. Logo, na área da assistência social as "crianças e adolescentes com até 15 anos em risco ou retiradas do trabalho infantil pelo Programa de Erradicação do Trabalho Infantil (Peti), devem participar dos Serviços de Convivência e Fortalecimento de Vínculos (SCFV) do Peti e obter frequência mínima de $85 \%$ da carga horária mensal."22.

O Poder Público tem o dever de fazer o acompanhamento gerencial para verificar o cumprimento dessas condicionalidades e, a partir disso, implementar ações de acompanhamento das famílias que não as cumprem. Segundo o MDS “a família que encontra dificuldades em cumprir as condicionalidades deve, além de buscar orientações com o gestor municipal do Bolsa Família, procurar o Centro de Referência de Assistência Social (Cras), o Centro de Referência Especializada de Assistência Social (Creas) ou a equipe de assistência social do município" 23 . Se não houver como sanar o descumprimento das condicionalidades, a família poderá ter o benefício bloqueado, suspenso ou até mesmo cancelado. Assim sendo, o MDS faz o acompanhamento das condicionalidades do programa de forma articulada com os Ministérios da Educação e da Saúde, além da participação municipal. Também, é importante frisar que, o acompanhamento dessas condicionalidades ocorre de acordo com calendários previamente acordados nas áreas que estão envolvidas. Esse calendário visa definir os períodos em que os municípios devem realizar o acompanhamento dessas famílias e fazer o registro de informações relativas às condicionalidades, sendo que essas informações serão informatizadas.

Esse programa atende famílias pobres com renda mensal por pessoa entre R\$77,01 e R\$ 154 e famílias extremamente pobres com renda mensal por pessoa de até $\mathrm{R} \$ 77^{24}$. Além de possuir diversos tipos de benefícios que serão utilizados para compor a parcela mensal que os beneficiários vão receber. Importante salientar que, esses benefícios serão baseados no perfil da família registrado no Cadastro

\footnotetext{
${ }^{20}$ BRASIL. MDS. <http://www.mds.gov.br/bolsafamilia $>$. Acesso em: 21 jun. 2014.

${ }^{21}$ BRASIL. MDS. <http://www.mds.gov.br/bolsafamilia $>$. Acesso em: 21 jun. 2014.

${ }^{22}$ BRASIL. MDS. <http://www.mds.gov.br/bolsafamilia $>$. Acesso em: 21 jun. 2014.

${ }^{23}$ BRASIL. MDS. 〈http://www.mds.gov.br/bolsafamilia $>$. Acesso em: 21 jun. 2014.

${ }^{24} \mathrm{O}$ benefício do Bolsa Família é variável, uma vez que é pago o valor suficiente para que uma família possua uma renda per capita mensal mínima de $\mathrm{R} \$ 70$ reais ( $\mathrm{R} \$ 77$ reais, a partir de junho de 2014).
}

\begin{tabular}{|c|c|c|c|c|c|}
\hline intuitio & $\begin{array}{c}\text { ISSN } \\
1983-4012\end{array}$ & Porto Alegre & Vol.8 $-\mathrm{N}^{\circ} .1$ & $\begin{array}{c}\text { Junho } \\
2015\end{array}$ & p.198-217 \\
\hline
\end{tabular}


Único e estas informações do CadÚnico consideram: "a renda mensal por pessoa, o número de integrantes, o total de crianças e adolescentes de até 17 anos, além da existência de gestantes" ${ }^{\text {"25 }}$. A regulamentação do Programa Bolsa Família vai estabelecer os seguintes tipos de benefícios:

Benefício Básico: R $\$ 77$ - Concedido apenas a famílias extremamente pobres (renda mensal por pessoa menor de até $\mathrm{R} \$ 77$ ). Benefício Variável de 0 a 15 anos: $\mathrm{R} \$ 35$ - Concedido às famílias com crianças ou adolescentes de 0 a 15 anos de idade. Benefício Variável à Gestante: R\$ 35 - Concedido às famílias que tenham gestantes em sua composição; Pagamento de nove parcelas consecutivas, a contar da data do início do pagamento do benefício, desde que a gestação tenha sido identificada até o nono mês; A identificação da gravidez é realizada no Sistema Bolsa Família na Saúde. O Cadastro Único não permite identificar as gestantes. Benefício Variável Nutriz: $\mathrm{R} \$ 35$ - Concedido às famílias que tenham crianças com idade entre 0 e 6 meses em sua composição ; Pagamento de seis parcelas mensais consecutivas, a contar da data do início do pagamento do benefício, desde que a criança tenha sido identificada no Cadastro Único até o sexto mês de vida. Observação: Os benefícios variáveis acima descritos são limitados a 5 (cinco) por família, mas todos os integrantes da família devem ser registrados no Cadastro Único. Benefício Variável Vinculado ao Adolescente: $\mathrm{R} \$ 42$ - Concedido a famílias que tenham adolescentes entre 16 e 17 anos limitado a dois benefícios por família. Benefício para Superação da Extrema Pobreza: calculado caso a caso - Transferido às famílias do Programa Bolsa Família que continuem em situação de extrema pobreza (renda mensal por pessoa de até $R \$ 77$ ), mesmo após o recebimento dos outros benefícios. Ele é calculado para garantir que as famílias ultrapassem o limite de renda da extrema pobreza $^{26}$.

Percebe-se que os valores recebidos pelas famílias do programa podem variar. É fundamental se saber que o Cadastro Único é um banco de dados que dará acesso a outros programas e políticas públicas sociais efetivadas pelo Governo Federal. Importante que se frise que, existem em parceria com os Estados e o Distrito Federal, além da Secretaria Nacional de Renda de Cidadania (Senarc) do Ministério do Desenvolvimento Social e Combate à Fome (MDS), ações de capacitação e disseminação de informações para os profissionais que atuam na gestão e na implementação do Programa Bolsa Família (PBF) e do Cadastro Único para Programas Sociais do Governo Federal (Cadastro Único) ${ }^{27}$. Destarte, de acordo com o MDS os principais objetivos da Senarc são:

capacitar estados, municípios, Instâncias de Controle Social (ICS) e parceiros, priorizando informações sobre instrumentos normativos, sistemas e procedimentos operacionais; apoiar ações de capacitação específicas dos estados, direcionadas a questões institucionais e operacionais do Bolsa Família e do Cadastro Único e planejar e executar capacitações continuadas ${ }^{28}$.

\footnotetext{
${ }^{25}$ BRASIL. MDS. <http://www.mds.gov.br/bolsafamilia〉. Acesso em: 21 jun. 2014.

${ }^{26}$ BRASIL. MDS. <http://www.mds.gov.br/bolsafamilia $>$. Acesso em: 21 jun. 2014.

${ }^{27}$ BRASIL. MDS. 〈http://www.mds.gov.br/bolsafamilia $>$. Acesso em: 21 jun. 2014.

${ }^{28}$ BRASIL. MDS. <http://www.mds.gov.br/bolsafamilia >. Acesso em: 21 jun. 2014.
}

\begin{tabular}{|c|c|l|l|l|l|}
\hline intuitio & $\begin{array}{c}\text { ISSN } \\
1983-4012\end{array}$ & Porto Alegre & Vol.8 $-\mathrm{N}^{\mathrm{o}} .1$ & $\begin{array}{c}\text { Junho } \\
2015\end{array}$ & p.198-217 \\
\hline
\end{tabular}


Essa estratégia de promover a capacitação desenvolvida por esta Secretaria (SENARC) vai levar em consideração a complexidade do Programa Bolsa Família e do Cadastro Único e as necessidades de ambientar e de preparar os atores/cidadãos envolvidos nos seus processos de gestão e operacionalização. “As atividades são realizadas presencialmente e/ou à distância, e os materiais de apoio - como apresentações, vídeos e apostilas - são disponibilizados por esta Secretaria" ${ }^{29}$. Além disso, o atendimento da Senarc às demandas de apoio às capacitações dos municípios é feito por meio das Coordenações Estaduais do programa Bolsa Família. De tal modo, os municípios devem encaminhar as solicitações de informações e de formação a essas instâncias, que arranjam apreciação e acolhimento e expedem a esta Secretaria uma solicitação de apoio técnico às capacitações descentralizadas. Para isso, as Coordenações Estaduais devem utilizar um formulário-padrão ${ }^{30}$.

A seguir se ponderará como é possível a aplicação da justiça como equidade de John Rawls no programa Bolsa Família.

\subsection{A justiça como equidade e sua aplicação ao Programa Social Federal de Transferência de Renda Bolsa Família}

O Programa Bolsa Família possui o mérito de trabalhar com um conceito de pobreza amplo, que não é ligado simplesmente aos quesitos de renda, mas significando também o acesso por parte desses beneficiários a serviços básicos como saúde e educação, entre outros. Isso vem reforçar a necessidade de se procurar trabalhar com políticas públicas que sejam interligadas, no intuito de promover o acesso da população a um número cada vez maior de serviços de proteção à família em sua integralidade, garantindo-lhes os direitos fundamentais básicos e o mínimo social/existencial.

O mínimo existencial vem a ser um conjunto de ocorrências materiais que são indispensáveis à existência humana digna, ou seja, o mínimo existencial está atrelado à dignidade da pessoa humana. Considera-se o mínimo existencial não apenas os bens para sobrevivência física, mas também os bens intelectuais e espirituais. Deste modo, o mínimo existencial vem representar um subconjunto dentro dos direitos sociais, econômicos e culturais. Diante destas observações, se o mínimo existencial não for efetivado e garantido na sociedade haverá a violação do princípio constitucional da dignidade da pessoa humana. Portanto, o Estado deve garantir as condições mínimas para que os cidadãos possam desenvolver e possuir condições reais de assegurar por si mesmos sua dignidade e respeito na sociedade. Ou seja, é a ideia de igualdade de oportunidades e da diferença trazida por John Rawls. A Constituição Federal de 1988 trouxe um Estado Democrático de Direito que defende a igualdade de resultados para todos os

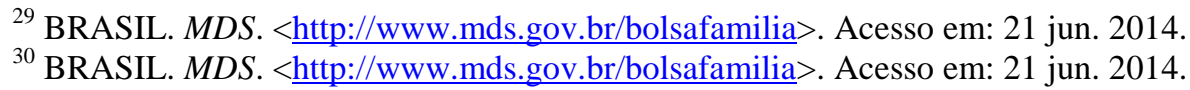

\begin{tabular}{|c|c|c|c|c|c|}
\hline intuitio & $\begin{array}{c}\text { ISSN } \\
1983-4012\end{array}$ & Porto Alegre & Vol.8 $-\mathrm{N}^{\mathrm{o}} .1$ & $\begin{array}{c}\text { Junho } \\
2015\end{array}$ & p.198-217 \\
\hline
\end{tabular}


cidadãos, onde se assegura um padrão de vida voltado à dignidade humana (art. 1, III da CF/88) e ao bem comum.

O mínimo existencial vem representar um conjunto de condições iniciais para o exercício da liberdade, ou seja, de direitos como, a alimentação, a saúde, a educação, habitação, etc., sendo uma parcela mínima sem a qual o cidadão não poderia sobreviver. Como Torres Lobo ${ }^{31}$ salienta a garantia do mínimo existencial é mais ampla do que somente a sobrevivência física, não podendo ser reduzido a uma noção de mínimo vital que é suficiente para que se assegure o exercício das liberdades fundamentais.

Para Weber "o fato é que não é possível fixar abstratamente o conteúdo desse mínimo existencial. Suas exigências podem variar de acordo com as condições econômicas, culturais e sociais de um povo"32. E, continua manifestando que "alguns parâmetros, no entanto, são, hoje, reconhecidos quanto ao que é necessário para uma vida digna. Os direitos sociais como a saúde, a educação e a habitação estão entre eles" ${ }^{33}$. Deste modo, "pode-se afirmar que o conteúdo do mínimo existencial é constituído basicamente pelos direitos fundamentais sociais, sobretudo aquelas "prestações materiais" que visam garantir uma vida digna"34. Weber continua afirmando que "isso não significa garantir apenas a sobrevivência física, mas implica no desenvolvimento da personalidade como um todo. Viver não é apenas sobreviver" 35 . Percebese que o mínimo existencial deve ser entendido como uma base para a vida humana, sendo um direito fundamental e essencial e que não necessita de lei infraconstitucional para a sua obtenção, pelo fato de ser inerente aos seres humanos. Esse direito está ligado à justiça social, ideia trazida na Constituição Federal de 1988, no art. 170. O mínimo se refere aos direitos relacionados às necessidades, mas não se reduz como já visto a um mínimo vital, que somente vai garantir condições vitais que são mínimas para a garantia da dignidade da pessoa humana em nosso Estado Democrático de Direito.

Esse direito tem de ser garantido pelo Estado, o qual deve oferecer condições para que exista a plena eficácia e aplicabilidade destes direitos. Esses direitos que abrangem o mínimo existencial são direitos de segunda geração, possuindo um caráter programático, devido ao fato do Estado ter de desenvolver programas e políticas públicas para que os mesmos sejam implementados e que todos os cidadãos possam usufruir. O mínimo existencial vai abranger o conjunto de prestações necessárias e essenciais para que todo o ser humano possa usufruir de uma vida digna. Para Weber a "dignidade da

\footnotetext{
${ }^{31}$ TORRES, Ricardo Lobo. O mínimo existencial e os direitos fundamentais. in RDA 177, jul/set, Rio de Janeiro, 1989.

32 WEBER, Thadeu. Ética e Filosofia do Direito: Autonomia e Dignidade da Pessoa Humana. Porto Alegre: Vozes, 2013, p. 208.

${ }^{33}$ WEBER, Thadeu. Ética e Filosofia do Direito: Autonomia e Dignidade da Pessoa Humana. Porto Alegre: Vozes, 2013, p. 208.

${ }^{34}$ WEBER, Thadeu. Ética e Filosofia do Direito: Autonomia e Dignidade da Pessoa Humana. Porto Alegre: Vozes, 2013, p. 208.

${ }^{35}$ WEBER, Thadeu. Ética e Filosofia do Direito: Autonomia e Dignidade da Pessoa Humana. Porto Alegre: Vozes, 2013, p. 208.
}

\begin{tabular}{|c|c|l|l|l|l|}
\hline intuitio & $\begin{array}{c}\text { ISSN } \\
1983-4012\end{array}$ & Porto Alegre & Vol.8 $-\mathrm{N}^{\mathrm{o}} .1$ & $\begin{array}{c}\text { Junho } \\
2015\end{array}$ & p.198-217 \\
\hline
\end{tabular}


pessoa humana como preceito ético e fundamento constitucional exige do Estado não só respeito e proteção, mas garantia de efetivação dos direitos dela decorrentes" ${ }^{36}$. Deste modo, "toda a pessoa é sujeito de direitos e deveres e como tal deve ser tratada"37. Portanto, "do ponto de vista jurídico, quando falamos de um "mínimo existencial" estamos tratando de algo intrinsecamente ligado à realização dos direitos fundamentais, que representam a concretização do princípio da dignidade da pessoa humana"38.

O Estado tem o dever de oferecer as prestações positivas de natureza assistencial, entre elas, o direito a assistência social, independente da contribuição para a seguridade social, a quem dela necessitar, sendo que essa previsão está contida na Constituição Federal de 1988, nos art. 203, 204 e 206, IV (que traz a previsão de gratuidade do ensino público em estabelecimentos oficiais). Verifica-se que existe um consenso acerca da não existência de uma vida digna, nem de mínimo existencial, nem da possibilidade de exercício de capacidades tanto individuais quanto coletivas, sem que haja determinadas condições básicas que sejam satisfeitas e introduzidas às pessoas. Mas quais condições seriam essas? São somente condições biológicas? As necessidades humanas vão além de condições biológicas ou naturais, envolvem outros aspectos como a produção de instrumentos que permitam um processo de interações sociais, de organização de espaço, de divisão de tarefas, de justiça social, ou seja, englobam as condições sociais, culturais, econômicas e mesmo as psicológicas.

O programa Bolsa Família é uma garantia de renda dissociada do trabalho, que vai além de garantir as condições mínimas de sobrevivência, atingindo a possibilidade de acesso a renda, a qual significa o seu poder de escolha no mercado capitalista consumista. Esse programa permite o incremento da possibilidade de aquisição de bens sociais, permitindo que possa haver a concretização constitucional de uma sociedade mais justa, fraterna e solidária, ou seja, de uma sociedade igual (isso ocorre comparado à situação anterior dos beneficiários que viviam em situação de vulnerabilidade social).

Destarte, o Programa Bolsa Família no que se refere aos princípios desenvolvidos pela teoria da justiça como equidade de John Rawls observa-se que os ideais de liberdade e igualdade são combinados para que haja a existência de uma sociedade justa. Portanto, Rawls entende que uma sociedade é justa quando as instituições repartem os bens principais de forma equitativa entre seus cidadãos, levando e consideração, o fato de que estes cidadãos são diferentes uns dos outros em questão de bens principais. Rawls traz a distinção de bens principais para a formulação das exigências de justiça. São eles: os bens primários sociais e os bens primários naturais. Segundo o autor: "os principais bens primários à disposição

\footnotetext{
${ }^{36}$ WEBER, Thadeu. Ética e Filosofia do Direito: Autonomia e Dignidade da Pessoa Humana. Porto Alegre: Vozes, 2013, p. 205.

${ }^{37}$ WEBER, Thadeu. Ética e Filosofia do Direito: Autonomia e Dignidade da Pessoa Humana. Porto Alegre: Vozes, 2013, p. 205.

${ }^{38}$ WEBER, Thadeu. Ética e Filosofia do Direito: Autonomia e Dignidade da Pessoa Humana. Porto Alegre: Vozes, 2013, p. 205.
}

\begin{tabular}{|c|c|l|l|l|l|}
\hline intuitio & $\begin{array}{c}\text { ISSN } \\
1983-4012\end{array}$ & Porto Alegre & Vol.8 $-\mathrm{N}^{\mathrm{o}} .1$ & $\begin{array}{c}\text { Junho } \\
2015\end{array}$ & p.198-217 \\
\hline
\end{tabular}


da sociedade sejam direitos, liberdade e oportunidades, renda e riqueza"39 são bens primários sociais. Já, os bens primários naturais seriam a "saúde e o vigor, a inteligência e a imaginação" 40 . Rawls trabalha em sua concepção de justiça com os bens primários sociais.

Portanto, o princípio da igualdade equitativa de oportunidades tem prevalência sobre o princípio da diferença, visto que Rawls busca evitar a troca de liberdades básicas por ganhos econômicos e sociais. Entende-se que o princípio da liberdade igual e o da igualdade equitativa de oportunidades são condições fundamentais para que exista a justiça social juntamente com o princípio da diferença.

O princípio da igualdade equitativa de oportunidades vem reforçar as oportunidades que devem ser asseguradas independentemente da posição social das pessoas, pois seria injusto que as pessoas mais dotadas de talentos, mas em piores situações sociais e econômicas não obtivessem chances semelhantes às demais pessoas. Rawls demonstra que o papel do Estado é fundamental, tanto na provisão de serviços quanto na distribuição de meios e na intervenção no setor privado, promovendo empregos, por exemplo. Desta forma, o Governo possibilita a oportunidade igual nos diversos setores, como educação e cultura para os indivíduos. Também a igualdade se dá na escolha das atividades econômicas e na escolha da profissão. Portanto, o Governo deve garantir um mínimo social, seja através de dotações familiares (como o salário-família) e pagamentos especiais por doença e desemprego, seja mais sistematicamente através de recursos tais como um suplemento de renda ${ }^{41}$. Mas, percebe-se que a igualdade equitativa de oportunidade não pode resolver o problema das dotações distintas de talentos individuais, visto que as posições vantajosas, mesmo que aberto a todos, vão ser preenchidas pelos mais talentosos. É a partir daí que aparece o princípio da diferença, onde se vai maximizar a distribuição de bens primários sociais aos menos favorecidos socialmente e garantir que as condições e meios indispensáveis sejam ampliados a cada um para que busquem realizar seu objetivo de vida.

O Programa Social Federal Bolsa Família vem promover o incremento dos bens primários sociais que são efetivados por políticas públicas, na área da educação, da saúde e da assistência social, com a finalidade de alterar a condição primária de desigualdade e possibilitar a participação dos menos favorecidos dentro da sociedade brasileira. A intervenção estatal é crucial para que a justiça social venha a se concretizar. Esse programa se articula em três dimensões fundamentais as de curto, médio e longo prazo, sendo elas: as de curto prazo seria o alívio imediato da pobreza por meio da transferência de renda; em médio prazo se possui o investimento em capital humano feito pelas condicionalidades inseridas no programa; e, por fim, em longo prazo, verifica-se o desenvolvimento social da família que se dá por meio de articulações com outras ações sociais e políticas públicas que já estão em curso no país, como por

\footnotetext{
${ }^{39}$ RAWLS, John. Uma teoria da Justiça. São Paulo: Martins Fonte, 2002, p. 66.

${ }^{40}$ RAWLS, John. Uma teoria da Justiça. São Paulo: Martins Fonte, 2002, p. 66.

${ }^{41}$ RAWLS, John. Uma teoria da Justiça. São Paulo: Martins Fonte, 2002, p. 305.
}

\begin{tabular}{|c|c|c|c|c|c|}
\hline intuitio & $\begin{array}{c}\text { ISSN } \\
1983-4012\end{array}$ & Porto Alegre & Vol.8 $-\mathrm{N}^{\circ} .1$ & $\begin{array}{c}\text { Junho } \\
2015\end{array}$ & p.198-217 \\
\hline
\end{tabular}


exemplo, a isenção de pagamento de taxas de inscrições em concurso público, o ProJovem Adolescente, o Programa de Erradicação do Trabalho Infantil, o programa Brasil Carinhoso, a aposentadoria para pessoas de baixa renda, o telefone popular, o Bolsa verde, a carteira do idoso, o programa de cisternas, o programa Minha Casa Minha Vida, a tarifa social de energia elétrica, a carta social e o passe livre para pessoas com deficiência, entre outros ${ }^{42}$.

O princípio da diferença exerce um importante papel na maximização da posição dos menos favorecidos levando em consideração o item de renda na lista de bens primários sociais, sendo este garantido pela distribuição de renda do programa Bolsa Família que cumpre a função redistributiva.

Conclui-se que existe a presença dos princípios teoria da justiça como equidade de Rawls no PBF. Deste modo, o princípio da liberdade igual é plenamente aplicável ao programa Bolsa Família, visto que garante em nosso sistema democrático a liberdade de consciência, a liberdade política de votar e ser votado, entre outras. Já, o princípio da igualdade equitativa de oportunidades, é contemplado no Programa Bolsa Família, na medida em que este é uma ação afirmativa com base material de romper o ciclo estrutural de pobreza e vulnerabilidade social existente no país. Ou seja, é a possibilidade de romper a condição básica que faz "o filho do pobre continuar pobre". Isso é permitido através das condicionalidades impostas pelo PBF, onde as famílias beneficiadas têm acesso a saúde, educação e assistência social, permitindo que se rompa o ciclo estrutural de pobreza existente.

No regime democrático, o acesso à oportunidade deve ser para todos os indivíduos visando garantir a igualdade tanto material quanto formal inserida na Constituição Federal de 1988. Esse programa abre a justa expectativa de igualdade de oportunidades por meio de um mínimo de renda para a sobrevivência descolada do trabalho, fazendo com que haja o funcionamento do mercado de trabalho. O programa Bolsa Família faz com que haja a introdução dos filhos das famílias beneficiárias nas escolas, daí a importância das condicionalidades. Porém, o objetivo é reduzir a pobreza e a desigualdade. Mas será possível criar uma sociedade que seja capaz de fazer com que os filhos das famílias pobres tenham habilidades similares aos filhos das famílias ricas? O princípio da diferença é plenamente aplicável ao programa Bolsa Família visto que é permitido que houvesse a desigualdade social desde que a mesma beneficie os menos favorecidos no contexto social brasileiro.

Para demonstrar a aplicação dos princípios de Rawls se estuda o aumento do consumo no Brasil após a implementação desse Programa Social Federal Bolsa Família. A seguir se fará uma análise do consumo advindo dos beneficiários do programa Bolsas Família através de dados de diversos indicadores sociais.

${ }^{42}$ BRASIL. MDS. <http://www.mds.gov.br/bolsafamilia $>$. Acesso em: 21 jun. 2014.

\begin{tabular}{|c|c|c|c|c|c|}
\hline intuitio & $\begin{array}{c}\text { ISSN } \\
1983-4012\end{array}$ & Porto Alegre & Vol.8 $-\mathrm{N}^{\circ} .1$ & $\begin{array}{c}\text { Junho } \\
2015\end{array}$ & p.198-217 \\
\hline
\end{tabular}


Cleide Calgaro, Thadeu Weber

Programa social federal de transferência de renda bolsa família e o consumo no Brasil: a presença da teoria da justiça de John Rawls

\section{O consumo advindo do Programa Bolsa Família e a presença Teoria de Justiça de John Rawls}

O benefício recebido pelas famílias do Programa Bolsa Família é um dos fatores de aumento popular do consumo de bens duráveis para casa, ou seja, produtos como eletrodomésticos, móveis e aparelhos eletrônicos. Segundo dado do $\mathrm{MDS}^{43}$ citando Rosa Maria Marques fica demonstrado que, qualquer aumento de renda para família pobres e extremamente pobres é prioritariamente destinado ao consumo de alimentos, mas o programa acaba tendo efeitos multiplicares nas economias locais. "O reflexo disso foi o aumento do consumo de bens duráveis entre as famílias muito pobres que recebem o Bolsa Família. Com o passar do tempo, as famílias ganharam segurança que vão receber o benefício e, assim, puderam destinar parte de sua renda para a compra a prazo de eletrodomésticos"44.

Rosa afirma que "o crescimento do consumo também está muito influenciado por outros fatores como elevação constante do salário mínimo, estabilidade monetária, aumento do número de trabalhadores com carteira assinada e ampliação do crédito consignado" 45 . Além disso, existe outro fator a ser considerado que é “o volume de recursos destinado pelo Bolsa Família em 2007, no total de R\$ 8,9 bilhões" ${ }^{\text {46 }}$. Para o ano de 2008 estão previstos 10,4 bilhões ${ }^{47}$. Sendo que "os valores repassados pelo Ministério do Desenvolvimento Social e Combate à Fome (MDS) beneficiam 11 milhões de famílias e, indiretamente, mais de 44 milhões de pessoas. "Isso representa quase $26 \%$ da população brasileira" 48 . Destarte, os recursos não beneficiam apenas os participantes do programa Bolsa Família, mas toda a economia, pois, "cada R 1 investido no Programa estimula um crescimento de $78 \%$ no Produto Interno Bruto (PIB) do Brasil e um efeito multiplicador de R\$ 2,40 sobre o consumo final das famílias"49.

De acordo com dados do IPEA, o Bolsa Família é o programa de transferência de renda que mais contribui para o país, a transferência social que mais contribui para o PIB. O Bolsa Família é também aquela que mais pesa no cálculo do consumo das famílias no País. "A cada R 1 transferido pelo Bolsa Família, o consumo final do total da economia aumenta $\mathrm{R} \$ 1,98$, enquanto que os efeitos no consumo

43 BRASIL. MDS. <http://www.mds.gov.br/saladeimprensa/noticias/2008/fevereiro/consumo-de-bens-duraveisaumenta-por-causa-do-bolsa-familia >. Acesso em: 21 jun. 2014.

44 BRASIL. MDS. <http://www.mds.gov.br/saladeimprensa/noticias/2008/fevereiro/consumo-de-bens-duraveisaumenta-por-causa-do-bolsa-familia >. Acesso em: 21 jun. 2014.

45 BRASIL. MDS. <http://www.mds.gov.br/saladeimprensa/noticias/2008/fevereiro/consumo-de-bens-duraveisaumenta-por-causa-do-bolsa-familia >. Acesso em: 21 jun. 2014.

46 BRASIL. MDS. <http://www.mds.gov.br/saladeimprensa/noticias/2008/fevereiro/consumo-de-bens-duraveisaumenta-por-causa-do-bolsa-familia >. Acesso em: 21 jun. 2014.

47 BRASIL. MDS. <http://www.mds.gov.br/saladeimprensa/noticias/2008/fevereiro/consumo-de-bens-duraveisaumenta-por-causa-do-bolsa-familia >. Acesso em: 21 jun. 2014.

48 BRASIL. MDS. <http://www.mds.gov.br/saladeimprensa/noticias/2008/fevereiro/consumo-de-bens-duraveisaumenta-por-causa-do-bolsa-familia >. Acesso em: 21 jun. 2014.

${ }^{49}$ BRASIL. MDS. <http://www.brasil.gov.br/cidadania-e-justica/2014/04/bolsa-familia-mantem-mais-de-434-6-milpessoas-fora-da-extrema-pobreza>. Acesso em: 21 jun. 2014.

\begin{tabular}{|c|c|c|c|c|c|}
\hline intuitio & $\begin{array}{c}\text { ISSN } \\
1983-4012\end{array}$ & Porto Alegre & Vol.8 - $\mathrm{N}^{\mathrm{o}} .1$ & $\begin{array}{l}\text { Junho } \\
2015\end{array}$ & p.198-217 \\
\hline
\end{tabular}


Programa social federal de transferência de renda bolsa família e o consumo no Brasil: a presença da teoria da justiça de John Rawls

final das famílias é ainda maior: de R\$2,4"50. Já, o programa Benefício de Prestação Continuada, no quesito consumo, é o que mais se aproxima do Bolsa Família, a "Cada R\$ 1 aplicado no BPC representa um retorno de R $\$ 1,32$ no consumo final da economia e de R \$ 1,54 no consumo das famílias" ${ }^{\text {"51 }}$. Segundos dados estatísticos:

\section{Gráfico 01 - Efeitos das transferências sociais sobre o consumo final}
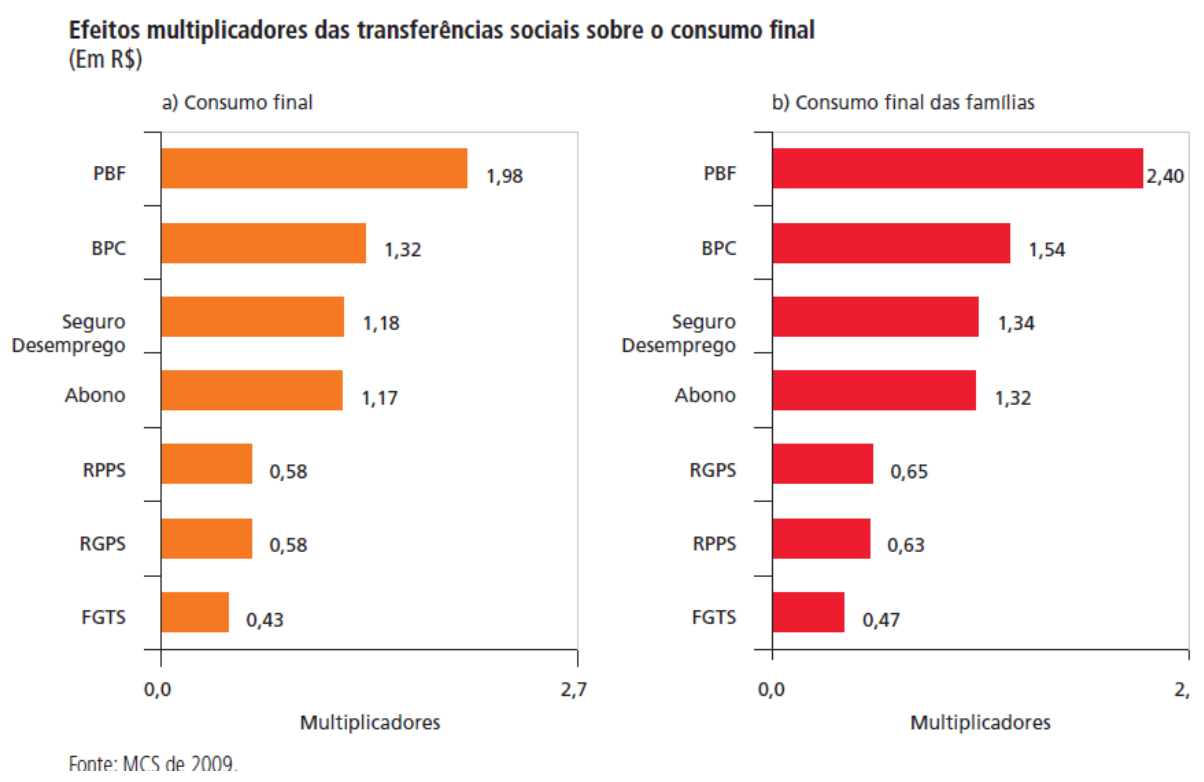

Fonte: Neri; Vaz; Souza, 2013, p. $202^{52}$.

Quanto mais direcionadas, as políticas de transferências de renda, aos mais pobres (os menos favorecidos), maior é o efeito que se verifica sobre o consumo. Os efeitos do PBF são maiores que as demais transferências feitas pelo Governo Federal. Para corroborar os dizeres acima se observa o gráfico abaixo, onde se pondera os efeitos macroeconômicos do programa Bolsa Família até o ano de 2013.

\section{Gráfico 02 - Gastos com programa Bolsa Família de 2003 a 2013}

50 BRASIL. ESTADÃO. 〈http://economia.estadao.com.br/noticias/geral,ipea-bolsa-familia-gera-o-maior-efeitosobre-consumo,167482e >. Acesso em: 21 jun. 2014.

51 BRASIL. ESTADÃO. <http://economia.estadao.com.br/noticias/geral,ipea-bolsa-familia-gera-o-maior-efeitosobre-consumo,167482e >. Acesso em: 21 jun. 2014.

52 NERI, Marcelo Côrtes. VAZ, Fabio Monteiro. SOUZA, Pedro Herculano Guimarães Ferreira de. Efeitos macroeconômicos do programa bolsa família: uma análise comparativa das transferências sociais. In: CAMPELLO, Tereza. NERI, Marcelo Côrtes. Programa Bolsa Família: uma década de inclusão e cidadania. Brasília: Ipea, 2013, p. 202.

\begin{tabular}{|c|c|l|l|l|l|}
\hline intuitio & $\begin{array}{c}\text { ISSN } \\
1983-4012\end{array}$ & Porto Alegre & Vol. $8-\mathrm{N}^{\circ} .1$ & $\begin{array}{c}\text { Junho } \\
2015\end{array}$ & p.198-217 \\
\hline
\end{tabular}


Cleide Calgaro, Thadeu Weber

Programa social federal de transferência de renda bolsa família e o consumo no Brasil: a presença da teoria da justiça de John Rawls

\begin{tabular}{|c|c|c|c|c|c|}
\hline \multirow[b]{2}{*}{ Ano } & \multicolumn{5}{|c|}{$\begin{array}{l}\text { Total destinado à ação Transferência de Renda Diretamente às Famílias } \\
\text { em Condição de Pobreza e Extrema Pobreza Lei n } 10836 \text { de 2004: }\end{array}$} \\
\hline & \multicolumn{2}{|c|}{ R\$ - Valor Corrente } & $\%$ PIB & \multicolumn{2}{|c|}{$\begin{array}{l}\text { Bilhões de R\$ - Valor } \\
\text { Constante }\end{array}$} \\
\hline 2003 & $\mathrm{R} \$$ & 509.984 .400 & $0,03 \%$ & $\mathrm{R} \$$ & 940 \\
\hline 2004 & $\mathrm{R} \$$ & 5.533 .257 .938 & $0,17 \%$ & $\mathrm{R} \$$ & 5.533 \\
\hline 2005 & $\mathrm{R} \$$ & 6.873 .978 .415 & $0,20 \%$ & $\mathrm{R} \$$ & 6.874 \\
\hline 2006 & $\mathrm{R} \$$ & 8.145 .378 .044 & $0,23 \%$ & $\mathrm{R} \$$ & 8.145 \\
\hline 2007 & $\mathrm{R} \$$ & 9.222 .092 .911 & $0,24 \%$ & $\mathrm{R} \$$ & 9.222 \\
\hline 2008 & $\mathrm{R} \$$ & 10.811 .168 .987 & $0,27 \%$ & $\mathrm{R} \$$ & 10.811 \\
\hline 2009 & $\mathrm{R} \$$ & 12.417 .041 .638 & $0,31 \%$ & $\mathrm{R} \$$ & 12.417 \\
\hline 2010 & $\mathrm{R} \$$ & 14.366 .015 .610 & $0,34 \%$ & $\mathrm{R} \$$ & 14.366 \\
\hline 2011 & $\mathrm{R} \$$ & 17.283 .104 .720 & $0,40 \%$ & $\mathrm{R} \$$ & 17.283 \\
\hline 2012 & $\mathrm{R} \$$ & 20.288 .877 .787 & $0,46 \%$ & $\mathrm{R} \$$ & 20.289 \\
\hline $2013^{*}$ & $\mathrm{R} \$$ & 24.890 .107 .091 & $0,56 \%$ & $\mathrm{R} \$$ & 24.890 \\
\hline \multicolumn{6}{|c|}{ IB Expectativa FOCUS } \\
\hline & & & TOTAL & $\mathrm{R} \$$ & $130.341,01$ \\
\hline & & & TOTAL * 1,78 & $\mathrm{R} \$$ & $232.006,99$ \\
\hline
\end{tabular}

Fonte: Finanças Fáceis, $2014^{53}$.

Deste modo, o programa Bolsa Família já distribuiu $\mathrm{R} \$ 130$ bilhões sendo que isso equivale a dizer que o impacto do PBF foi de cerca de R $\$ 232$ bilhões.

Conforme estudos dos Efeitos macroeconômicos do Programa Bolsa Família foi feito uma análise comparativa das transferências sociais que mostra o impacto do programa Bolsa Família na redução das desigualdades sendo de "369\% maior em relação aos benefícios previdenciários em geral e 86\% maior se comparado ao Benefício de Prestação Continuada (BPC), que é pago a idosos e pessoas com deficiência" ${ }^{54}$. Também, no que se refere ao consumo de bens produzidos nacionalmente houve uma estimulação do mercado interno e a criação de um mercado consumidor de massas. "O estudo aponta que 183.001 vagas de emprego foram geradas apenas em Sergipe, com impacto de R \$ 3,8 bilhões no valor da produção do estado, de R $\$ 639$ milhões nos salários e de R\$ 569 milhões na arrecadação tributária",55. Pode-se compreender o impulso do programa Bolsa Família no consumo dos beneficiários do programa, verificando-se um impacto no PIB nacional. Além do que, o programa Bolsa Família foi responsável por " $28 \%$ da queda da extrema pobreza, sendo que entre 2002 e 2012, a proporção de brasileiros vivendo com menos de $\mathrm{R} \$ 70$ caiu de $8,8 \%$ para $3,6 \%, 36$.

${ }^{53}$ BRASIL. Finanças Fáceis. 〈http://financasfaceis.wordpress.com/2014/02/24/estrategias-da-politica-economicarecente-4/>. Acesso em: 23 jun. 2014

${ }_{54}$ BRASIL. MDS. <http://www.brasil.gov.br/cidadania-e-justica/2014/04/bolsa-familia-mantem-mais-de-434-6-milpessoas-fora-da-extrema-pobreza>. Acesso em: 21 jun. 2014.

55 BRASIL. MDS. <http://www.brasil.gov.br/cidadania-e-justica/2014/04/bolsa-familia-mantem-mais-de-434-6-milpessoas-fora-da-extrema-pobreza>. Acesso em: 21 jun. 2014.

56 BRASIL. UOL. <http://economia.uol.com.br/noticias/infomoney/2013/10/15/bolsa-familia-gera-grandeinfluencia-no-consumo-e-no-pib-diz-ipea.htm>. Acesso em: 22 jun.2014

\begin{tabular}{|c|c|l|l|l|l|}
\hline intuitio & $\begin{array}{c}\text { ISSN } \\
1983-4012\end{array}$ & Porto Alegre & Vol.8 $-\mathrm{N}^{\circ} .1$ & $\begin{array}{c}\text { Junho } \\
2015\end{array}$ & p.198-217 \\
\hline
\end{tabular}


O programa Bolsa Família além de ser um programa barato vem realizar um forte giro na economia nacional. Deste modo, com a transferência de renda para famílias pobres e extremamente pobres, ou seja, em situação de vulnerabilidade social, há um aumento do consumo e da produção de bens garantindo que os princípios que a teoria de justiça como equidade de John Rawls sejam propagados.

\section{Considerações finais}

Buscou-se ponderar no presente trabalho se o Programa Social Federal de Transferência de Renda Bolsa Família se ajusta a uma ótica do justo na distribuição de riquezas sociais, consoante à teoria da justiça como equidade de John Rawls, e se este pode estabelecer, em articulação com todo um conjunto de suas condicionalidades, uma possibilidade real de superação da pobreza e da extrema pobreza para as famílias beneficiárias e, consequentemente, um mecanismo de inserção econômica e social na coletividade social. Importante que se ressalte que o Programa Bolsa Família não é um instrumento suficiente para a redução das desigualdades sociais. Deve haver por parte do Governo Federal estratégias amplas de desenvolvimento econômico, cultural e social.

A conclusão que se chega é que os princípios da justiça como equidade de John Rawls estão plenamente presentes ao Programa Social Federal de Transferência de Renda Bolsa Família. Além do que, esse programa impulsiona fortemente o mercado nacional e o PIB como demonstrado anteriormente, no presente trabalho. No que se refere aos princípios da justiça existentes na teoria da justiça de Rawls podese resumi-los da seguinte maneira:

1) Princípio da liberdade igual: a sociedade deve assegurar a máxima liberdade para cada pessoa, compatível com a liberdade igual para os demais.

2) Princípio da igualdade equitativa de oportunidade: as desigualdades econômicas e sociais devem estar ligadas a postos e a posições que sejam acessíveis a todos em condições de justa igualdade de oportunidade.

3) Princípio da diferença: a sociedade deve promover a distribuição igual da riqueza, exceto se a existência de desigualdades econômicas e sociais gerarem maior benefício para as pessoas menos favorecidas.

Mas existe uma série de aspectos a serem discutidos sobre esse programa Bolsa Família e a presença da teoria da justiça como equidade de John Rawls:

a) No aspecto político existe legitimidade do PBF junto à sociedade brasileira, demonstrando o nível de conhecimento da política e mesmo o apoio para a sua existência. Além do que o PBF é um programa barato ao Governo Federal e estimula o consumo e o crescimento no país.

\begin{tabular}{|c|c|l|l|l|l|}
\hline intuitio & $\begin{array}{c}\text { ISSN } \\
1983-4012\end{array}$ & Porto Alegre & Vol.8 $-\mathrm{N}^{\mathrm{o}} .1$ & $\begin{array}{c}\text { Junho } \\
2015\end{array}$ & p.198-217 \\
\hline
\end{tabular}


b) No aspecto social, a opinião pública deve ser considerada como elemento importante para a avaliação dessas políticas públicas, pois não se trata apenas de verificar se há apoio ou rejeição do programa, se o mesmo é um direito ou um assistencialismo, mas de entender que a análise adequada da população contribui para uma real e maior efetivação do programa.

c) No campo jurídico é preciso que se analisem as condicionalidades que podem efetivar no estabelecimento dessa política pública de transferência de renda focando nos elementos como a inclusão/exclusão e mesmo a solidariedade social, garantindo e efetivando uma série de direitos fundamentais individuais e mesmo sociais.

d) No campo da filosofia política e social pode-se observar a presença dos princípios da liberdade igual, da igualdade equitativa de oportunidades e da diferença, princípios esses advindos da teoria da justiça de John Rawls. É forte na sociedade (principalmente observando os dados estatísticos de indicadores sociais) a percepção de que o PBF contribui para proporcionar melhorias para a vida das pessoas, das famílias, das comunidades e garantir direitos fundamentais. Por fim, é importante ouvir a opinião pública da sociedade brasileira acerca do tema, e não se limitar a opinião dos beneficiários.

Não há como negar que para os pobres e extremamente pobres, houve a aquisição de direitos fundamentais sociais e individuais e a ligação com aspectos ligados a autoestima dos beneficiários. Mas a avaliação dessas políticas públicas não deve ficar somente no aspecto econômico, é preciso verificar os impactos entre os beneficiários e os não beneficiários para se entender os verdadeiros efeitos do programa.

Questiona-se a partir do exposto se o Programa Bolsa Família não pode se tornar uma forma de assistencialismo ou caridade no Brasil, fazendo com que os seus beneficiários fiquem dependentes do mesmo. Ou seja, o programa não pode ser um fim, mas deve ser um meio de extinguir a pobreza no Brasil. Outra questão a ser observada é a lógica contraditória do PBF, onde o mesmo é barato e vantajoso politicamente ao Governo Federal, permitindo ser uma estratégia de captação de votos na sociedade, por isso deve ser uma política pública de Estado e não de Governo, permitindo que seus objetivos possam se alcançados independente de construção partidária. Importante salientar que o PBF é uma construção, ao longo do tempo, de diversos Governos.

No aspecto de garantia de direitos fundamentais sociais e individuais, questiona-se se o mínimo existencial é o suficiente para os beneficiários, entende-se que houve a aquisição desses direitos, mas os mesmos sofrem de uma deficiência crônica na sociedade brasileira atual. Ou seja, para os beneficiários do PBF, houve uma garantia dos direitos fundamentais sociais e individuais, se pautado na condição social que viviam anteriormente, ou seja, em pobreza e extrema pobreza, caracterizando situação de vulnerabilidade social. Mas em comparação com os mais favorecidos isso já não ocorre. É preciso lembrar que não basta ter o mínimo vital/mínimo existencial para o consumo, é preciso se ter dignidade, acesso à

\begin{tabular}{|c|c|c|c|c|c|}
\hline intuitio & $\begin{array}{c}\text { ISSN } \\
1983-4012\end{array}$ & Porto Alegre & Vol.8 $-\mathrm{N}^{\circ} .1$ & $\begin{array}{c}\text { Junho } \\
2015\end{array}$ & p.198-217 \\
\hline
\end{tabular}


cultura, educação e assistência social digna num país que se diz uma REPÚBLICA DEMOCRÁTICA DE DIREITO.

\section{Referências}

BRASIL. ESTADÃO. <http://economia.estadao.com.br/noticias/geral,ipea-bolsa-familia-gera-o-maior-efeito-sobreconsumo,167482e>. Acesso em: 21.jun.2014.

BRASIL. Finanças Fáceis. <http://financasfaceis.wordpress.com/2014/02/24/estrategias-da-politica-economicarecente-4/>. Acesso em: 23.jun.2014

BRASIL. Instituto Brasileiro de Análise Social e Econômicas - IBASE. <http://www.ibase.br/pt/biblioteca-2/>. Acesso em: 21.jun.2014

BRASIL. MDS. <http://www.brasil.gov.br/cidadania-e-justica/2014/04/bolsa-familia-mantem-mais-de-434-6-milpessoas-fora-da-extrema-pobreza>. Acesso em: 21.jun.2014

BRASIL. MDS. <http://www.mds.gov.br/bolsafamilia>. Acesso em: 21.jun.2014

BRASIL. MDS. <http://www.mds.gov.br/saladeimprensa/noticias/2008/fevereiro/consumo-de-bens-duraveisaumenta-por-causa-do-bolsa-familia>. Acesso em: 21.jun.2014

BRASIL. UOL. <http://economia.uol.com.br/noticias/infomoney/2013/10/15/bolsa-familia-gera-grande-influenciano-consumo-e-no-pib-diz-ipea.htm >. Acesso em: 22.jun.2014

CALGARO, Cleide. Programas de transferência de renda: atores e políticas públicas na reconfiguração do estado contemporâneo. Curitiba: Juruá, 2013.

NERI, Marcelo Côrtes. VAZ, Fabio Monteiro. SOUZA, Pedro Herculano Guimarães Ferreira de. Efeitos macroeconômicos do programa bolsa família: uma análise comparativa das transferências sociais. In: CAMPELLO, Tereza. NERI, Marcelo Côrtes. Programa Bolsa Família: uma década de inclusão e cidadania. Brasília: Ipea, 2013.

RAWLS, John. Justiça como eqüidade. Trad.: Claudia Berliner. São Paulo: Martins Fontes, 2003.

O direito dos povos. São Paulo: Martins Fonte, 2001.

O liberalismo Político. São Paulo: Ática, 2000.

. Uma teoria da Justiça. São Paulo: Martins Fonte, 2002.

. A ideia de Razão Pública revisitada.(Org.) WERLE, Denilson Luis; MELO, Rúrion Soares.

Democracia deliberativa. São Paulo: Editora Singular, 2007.

TORRES, Ricardo Lobo. O mínimo existencial e os direitos fundamentais. in RDA 177, jul/set, Rio de Janeiro, 1989.

WEBER, Thadeu. Ética e Filosofia do Direito: Autonomia e Dignidade da Pessoa Humana. Porto Alegre: Vozes, 2013. . Ética e Filosofia: Hegel e o formalismo kantiano. Porto Alegre: Edipucrs, 1999.

Recebido em: 11/09/2014

Aprovado para publicação em: 23/02/2015

\begin{tabular}{|c|c|c|c|c|c|}
\hline intuitio & $\begin{array}{c}\text { ISSN } \\
1983-4012\end{array}$ & Porto Alegre & Vol.8 $-\mathrm{N}^{\circ} .1$ & $\begin{array}{c}\text { Junho } \\
2015\end{array}$ & p.198-217 \\
\hline
\end{tabular}

